\title{
Gene Polymorphisms in CCR5, CCR2, CX3CR1, SDF-1 and RANTES in Exposed but Uninfected Partners of HIV-1 Infected Individuals in North India
}

\author{
PALLIKUTH SURESH, ${ }^{1}$ AJAY WANCHU,${ }^{1,3}$ RAVINDER KAUR SACHDEVA, ${ }^{1}$ and ARCHANA BHATNAGAR ${ }^{2}$
}

\section{Published online: 28 December 2006}

In the XML version of this article (Journal of Clinical Immunology, Vol. 26, No. 5, September 2006, pp. 476484; DOI: 10.1007/s10875-006-9036-0), some of the entries in Table II were misidentified. We reprint it here in its entirety:

Springer regrets the error.
The online version of the original article can be found at http://dx.doi.org/10.1007/s10875-006-9036-0

\footnotetext{
${ }^{1}$ Department of Internal Medicine, Post Graduate Institute of Medical Education and Research, Chandigarh, India.

${ }^{2}$ Department of Biochemistry, Panjab University, Chandigarh, India.

${ }^{3}$ Department of Internal Medicine, Post Graduate Institute of Medical Education and Research, Chandigarh 160012, India.
}

Table II. Frequency of CCR2, SDF-1, CX3CR1-249I, CX3CR1280M, RANTES-28G, RANTES-403A Genotypes in EU Individuals and Healthy Controls and HIV Infected Controls

\begin{tabular}{lccc}
\hline \multicolumn{1}{c}{ Genotype } & EU & HC & HIV infected \\
& $n=35(\%)$ & $n=75(\%)$ & $n=50(\%)$ \\
\hline CCR2-V64I & & & \\
Wild & $24(68.5)$ & $56(74.6)$ & $36(72)$ \\
Heterozygous & $10(28.5)$ & $17(22.6)$ & $12(24)$ \\
Homozygous & $1(2.8)$ & $2(2.6)$ & $1(2)$ \\
CX3CR1 T280M & & & \\
Wild & $23(65.7)$ & $50(66.6)$ & $35(70)$ \\
Heterozygous & $12(34.28)$ & $25(33.3)$ & $15(30)$ \\
Homozygous & 0 & 0 & 0 \\
CX3CR1 V249I & & & \\
Wild & $27(77.1)$ & $57(76)$ & $37(74)$ \\
Heterozygous & $7(20)$ & $15(20)$ & $12(24)$ \\
Homozygous & $1(2.8)$ & $3(4)$ & $1(2)$ \\
SDF1 3'A & & & \\
Wild & $22(65.7)$ & $56(74.6)$ & $35(70)$ \\
Heterozygous & $11(31.4)$ & $16(21.3)$ & $13(26)$ \\
Homozygous & $2(5.7)$ & $3(4)$ & $2(4)$ \\
RANTES 28C/G & & & \\
Wild & $34(97.1)$ & $73(97.3)$ & 50 \\
Heterozygous & $1(2.8)$ & $2(2.6)$ & 0 \\
Homozygous & 0 & 0 & 0 \\
RANTES403G/A & & & \\
Wild & $23(65.7)$ & $59(78.6)$ & $36(72)$ \\
Heterozygous & $11(31.4)$ & $14(18.6)$ & $11(22)$ \\
Homozygous & $1(2.8)$ & $2(2.6)$ & $2(4)$ \\
\hline
\end{tabular}

Note. There was no difference in the genotype frequency for any gene between the three groups. 